\title{
Bisphosphonate prescribing, persistence and cumulative exposure in Ontario, Canada
}

\author{
A. M. Burden • J. M. Paterson • D. H. Solomon • \\ M. Mamdani • D. N. Juurlink • S. M. Cadarette
}

Received: 14 October 2010 / Accepted: 15 March 2011 /Published online: 21 May 2011

(C) The Author(s) 2011. This article is published with open access at Springerlink.com

\begin{abstract}
Summary We studied new users of oral bisphosphonates and found that less than half persisted with therapy for 2 years, and interruptions in use were common. During a median observation period of 4.7 years, $10 \%$ of patients filled only a single prescription, $37 \%$ switched therapies and median cumulative exposure was 2.2 years.

Introduction We sought to describe bisphosphonate prescribing, persistence and cumulative exposure among seniors in Ontario, Canada.

Methods We used Ontario Drug Benefit pharmacy claims to identify residents aged $\geq 66$ years who initiated oral bisphosphonate therapy between April 1996 and March 2009. The first date of bisphosphonate dispensing was considered the index date. Persistence with therapy was defined as continuous treatment with no interruption
\end{abstract}

A. M. Burden $\cdot$ M. Mamdani $\cdot$ S. M. Cadarette $(\bowtie)$

Leslie Dan Faculty of Pharmacy, University of Toronto,

144 College Street,

Toronto, ON, Canada M5S 3M2

e-mail: s.cadarette@utoronto.ca

J. M. Paterson · M. Mamdani - S. M. Cadarette

Institute for Clinical Evaluative Sciences,

Toronto, ON, Canada

J. M. Paterson · M. Mamdani

Department of Health Policy, Management and Evaluation,

Faculty of Medicine, University of Toronto,

Toronto, ON, Canada

J. M. Paterson

Department of Family Medicine, McMaster University,

Hamilton, ON, Canada exceeding 60 days. We examined persistence with therapy and the number of extended gaps ( $>60$ days) between prescriptions over time periods ranging from 1 to 9 years. We also identified the proportion of patients filling only a single prescription and switching to a different bisphosphonate, and calculated the median days of exposure irrespective of gaps in therapy.

Results A total of 451,113 eligible new bisphosphonate users were identified: mean age $=75.6$ years $(\mathrm{SD}=6.9), 84 \%$ female, and median follow-up length $=4.7$ years. Persistence with therapy declined from $63 \%$ at 1 year to $46 \%$ at 2 years and $12 \%$ at 9 years. Among those with at least 5 years of follow-up $(n=213,029), 61 \%$ had one or more extended gaps in bisphosphonate therapy. Overall, $10 \%$ of patients filled only a single prescription, $37 \%$ switched to a different bisphosphonate and the median exposure was 2.2 years.

\footnotetext{
J. M. Paterson

Centre for Evaluation of Medicines, St. Joseph's Healthcare,

Hamilton, ON, Canada

D. H. Solomon

Division of Rheumatology, Immunology and Allergy

and Division of Pharmacoepidemiology and Pharmacoeconomics,

Brigham and Women's Hospital, Harvard Medical School,

Boston, MA, USA

M. Mamdani

Applied Health Research Centre, Li Ka Shing Knowledge

Institute, St. Michael's Hospital, University of Toronto,

Toronto, ON, Canada

D. N. Juurlink

Sunnybrook Research Institute,

Toronto, ON, Canada
} 
Conclusion Less than half of patients persisted with bisphosphonate therapy for 2 years and interruptions in therapy were common, with most patients experiencing two or more $>60$-day gaps in therapy. Interventions are needed to improve persistence with bisphosphonate therapy and reduce the frequency of gaps in treatment.

Keywords Alendronate $\cdot$ Etidronate $\cdot$ Medication persistence $\cdot$ Osteoporosis $\cdot$ Risedronate

\section{Introduction}

Osteoporosis is a major public health concern that results in considerable fracture-related morbidity and mortality [1-3]. In Canada, oral bisphosphonates (alendronate, etidronate, and risedronate) are the most commonly prescribed agents for treating osteoporosis and preventing fractures [3, 4]. However, persistence with therapy is suboptimal and linked to reduced drug effectiveness [58]. Prior systematic reviews document that fewer than half of patients persist with osteoporosis treatment for a full year $[5,9,10]$, with estimates ranging between $18 \%$ and $78 \%$ for bisphosphonates $[11,12]$. An underreported finding is that many patients who discontinue bisphosphonate therapy reinitiate treatment after an extended gap [13]. To further explore this issue, we studied all new users of oral bisphosphonates among older adults in Ontario from April 1996 to March 2009. We hypothesized that the majority of patients would discontinue treatment, yet a significant proportion would return to therapy after an extended gap in therapy. We also hypothesized that many patients would experience more than one extended gap in therapy, yet cumulative exposure to oral bisphosphonates would exceed 1 full year of therapy in most patients.

\section{Methods}

Data sources

We used Ontario healthcare utilization (medical and pharmacy) databases to identify, characterize and follow all new users of oral bisphosphonates aged 66 or more years in Ontario since 1996. Ontario medical and pharmacy claims databases are widely used for research purposes, and several studies demonstrate data quality [14-18]. Medicare services are funded through comprehensive universal health insurance for all Canadian residents, and residents of Ontario aged 65 or more years qualify for pharmacy coverage through the Ontario Drug Benefit (ODB) program [19]. The ODB Formulary has included unrestricted access to cyclical etidronate since 1996 and alendronate and risedronate since 2007.

Study cohort

We identified new users of alendronate $(5,10$, and $70 \mathrm{mg}$ ), cyclical etidronate and risedronate (5 and $35 \mathrm{mg}$ ) using ODB program data from April 1, 1996 to March 31, 2009. The first date of bisphosphonate dispensing over the entire study period was considered the index date. To ensure a minimum 1 full year of pharmacy claims history, we restricted inclusion to those aged 66 years or older at index date. We also excluded patients with Paget's disease diagnosis and patients with any prescription related to osteoporosis (bisphosphonate, calcitonin, raloxifene, or teriparatide) in the year prior to the index date. For descriptive purposes, we defined age at index, and identified bone mineral density (BMD) testing, and fracture history within 1 year prior to the index date (Appendix 1). BMD testing was identified using billing codes for Dual-Photon Absorptiometry (DPA) prior to 1998 and Dual-energy X-ray Absorptiometry (DXA) from 1998 to 2009. These codes have an estimated sensitivity of $98 \%$ and specificity of $93 \%$ for identifying BMD testing in Ontario [18]. Fractures were identified using outpatient and inpatient billing claims. Prior to April 2002, inpatient diagnoses were coded using ICD ninth revision, clinical modification (ICD-9-CM). Since then, the Canadian tenth revision (ICD-10-CA) codes have been used.

\section{Measuring persistence with therapy}

We determined persistence with therapy using ODB (pharmacy claims) data. ODB data include the days supplied and thus we can calculate when a patient is expected to refill their prescription. We defined persistence as continuous treatment without an interruption (gap) exceeding 60 days (Fig. 1). In a secondary analysis, we extended the permissible gap length to 120 days. These gap lengths are consistent and comparable with prior research on persistence with osteoporosis pharmacotherapy [20-23]. When calculating persistence, overlap of the same drug and regimen was additive; however, a switch between agents or from daily to weekly dosing of the same drug was considered continuous use with no overlap granted. Values for missing days supplied were imputed prior to 1997 when this field was not reported in the ODB database; this included 13 patients dispensed alendronate ( 24 dispensing records), and all patients dispensed cyclical etidronate prior to 1997 . We imputed a 60-day supply for alendronate-the median number of days supply for alendronate from 1997 to 


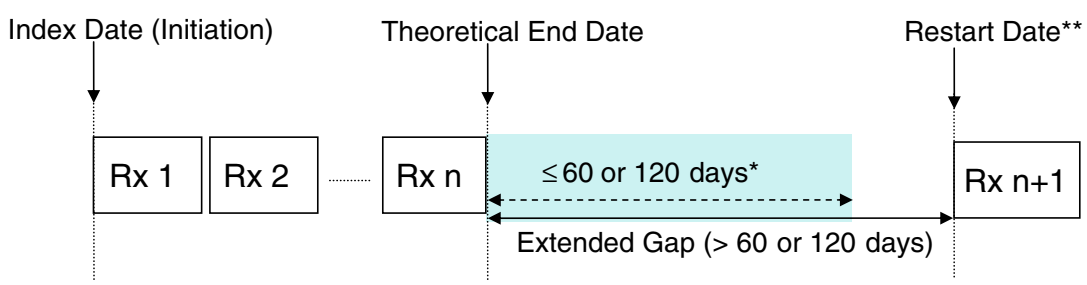

Fig. 1 Defining persistence with therapy (adapted from Cadarette et al. [33]). Persistence with therapy after index was defined as continuous treatment without a gap $>60$ days (primary analysis) and $>120$ days (secondary analysis). Theoretical end of treatment must have occurred within the follow-up interval under investigation; however, pharmacy data after the theoretical treatment end date were used to identify whether or not an extended gap was

1999. A 90-day supply was imputed for cyclical etidronate since it is dispensed as 14 days of active drug plus 76 days of calcium supplements.

Statistical analysis

We compared the characteristics (age, sex, bisphosphonate at index, prior BMD testing, and fracture history) of new users across four time periods: April 1996March 2000, April 2000-March 2003, April 2003March 2006, and April 2006-March 2008. We then examined persistence with therapy and number of extended gaps (primary analysis gap length $>60$ days and secondary analysis gap length $>120$ days) between prescriptions according to follow-up periods ranging from 1 to 9 years after treatment initiation. Only those persons with complete follow-up information were included in each respective follow-up period, and therefore patients who died within the observation period were excluded from respective analyses. In a secondary analysis, we examine the length of time until return to therapy following a 120-day gap or longer by plotting a Kaplan-Meier curve that censored patients at time of death, emigration from the province or March 31, 2009- the last date of available data. Finally, we calculated the proportion of patients that filled only a single prescription, the proportion that switched to a different bisphosphonate, and the median days of exposure within 1 year after index, and over the entire follow-up period.

\section{Results}

Descriptive characteristics

We identified 451,113 new bisphosphonate users meeting our inclusion criteria. Of these, $84 \%$ were female and the mean age was 75.6 years $(S D=6.9)$. From April 2000 to relevant to define non-persistence. *If the gap length between prescriptions was $\leq 60$ days, then the patient was assumed to have persisted with therapy. **Example when a patient reinitiates therapy after an extended gap. Some patients never reinitiate treatment and are defined in Table 2 as having discontinued therapy. $\mathrm{Rx}=$ Prescription

March 2009 fiscal year groups, we found that the proportion of male users increased over time (from $8.9 \%$ to $23.6 \%$ ), etidronate use at index declined over time (from $91.0 \%$ to $22.5 \%$ ), and BMD testing prior to treatment initiation has been stable at $63 \%$ since 2000 (Table 1).

\section{Persistence with bisphosphonate therapy}

A summary of persistence with bisphosphonate therapy over time is provided in Table 2. In our primary analysis that used a 60-day permissible gap, we identified that the proportion of patients that persisted with therapy declined from $63 \%$ at 1 year to $12 \%$ after 9 years. We also identified that most patients experienced one or more extended gaps in bisphosphonate therapy. For example, among the 213,029 new users with at least 5 years of follow-up, $25 \%$ persisted with therapy for the full 5 years, $61 \%$ experienced one $(24 \%)$ or more $(37 \%)$ extended gaps in therapy, and $14 \%$ discontinued treatment without returning to bisphosphonate therapy. Using a more lenient 120-day permissible gap to define non-persistence, we note that persistence rates increased and fewer users were identified to have experienced extended gaps in drug therapy. For example, persistence at 1 year increased from $63 \%$ using a 60 -day permissible gap to $77 \%$ when using a 120-day permissible gap (Table 2). Figure 2 represents the Kaplan-Meier curve for time until treatment reinitiation after at least 120 days without drug, that censors on date of death, and loss to follow-up. Here we note that $38 \%$ of patients returned to therapy within 1 year, $51 \%$ returned within 2 years, and $67 \%$ returned to therapy within 5 years.

Number of prescriptions, total drug exposure and drug switching

Patients were followed for a median length of 4.7 years $(\min =0.5$ years, $\max =12.8$ years). During the first year of 
Table 1 Characteristics of new users of oral bisphosphonates ${ }^{\mathrm{a}}$ : Ontario residents aged 66 or more years, April 1996-March 2009

\begin{tabular}{|c|c|c|c|c|c|}
\hline & $\begin{array}{l}\text { April 1996-March } \\
2000 \\
N=106,456\end{array}$ & $\begin{array}{l}\text { April 2000-March } \\
2003 \\
N=119,468\end{array}$ & $\begin{array}{l}\text { April 2003-March } \\
2006 \\
N=119,326\end{array}$ & $\begin{array}{l}\text { April 2006-March } \\
2009 \\
N=105,863\end{array}$ & $\begin{array}{l}\text { Overall } \\
N=451,113\end{array}$ \\
\hline Age, mean (SD) & $75.1(6.4)$ & $75.4(6.7)$ & $76.0(7.1)$ & $75.6(7.2)$ & $75.6(6.9)$ \\
\hline Males, $\%$ & 8.9 & 13.3 & 19.8 & 23.6 & 16.4 \\
\hline Etidronate, $\%$ & 91.0 & 89.5 & 55.3 & 22.5 & 65.1 \\
\hline BMD test, $\%{ }^{\mathrm{b}}$ & 58.1 & 63.6 & 63.3 & 63.2 & 62.1 \\
\hline \multicolumn{6}{|l|}{ Fracture history, $\%{ }^{\mathrm{c}}$} \\
\hline Thoracic vertebral & 0.1 & 0.2 & 0.2 & 0.2 & 0.2 \\
\hline Hip, humerus, radius/ulna & 5.4 & 5.5 & 6.2 & 6.5 & 5.9 \\
\hline
\end{tabular}

${ }^{a}$ Alendronate $(5,10$, and $70 \mathrm{mg})$, cyclical etidronate and risedronate $(5$ and $35 \mathrm{mg})$.

${ }^{\mathrm{b}}$ BMD testing identified within 1 year prior to index date using Ontario Health Insurance Plan (OHIP) billing codes for dual photon absorptiometry (DPA) prior to 1998, and dual-energy X-ray absorptometry (DXA) from 1998 to 2009 (see Appendix 1).

${ }^{\mathrm{c}}$ Fractures were identified using ICD-9-CM codes before April 2002, and ICD-10-CA codes since April 2002 (see Appendix 1).

therapy, $16 \%$ of users received only a single prescription of an oral bisphosphonate; however, this decreased to $10 \%$ when considering the entire follow-up period of up to 12.8 years. The median length of time covered by bisphosphonates before a period greater than 60 days without treatment was 0.9 years ( $\mathrm{SD}=2.5$ years), and this increased to 2.2 years $(\mathrm{SD}=2.8$ years) when considering all episodes of use.
We found that $7 \%$ of new bisphosphonate users switched to a different bisphosphonate within 1 year of treatment initiation, and this increased to more than a third of patients (37\%) over the entire duration of follow-up. Although fewer than $8 \%$ of etidronate users who initiated therapy between 1996 and 2003 switched to a different bisphosphonate within the first year of therapy, this increased to $51 \%$ over the entire follow-up period of up

Table 2 Proportion of new oral bisphosphonate ${ }^{\mathrm{a}}$ users who persisted ${ }^{\mathrm{b}}$ with therapy, discontinued therapy ${ }^{\mathrm{c}}$ and experience one or more extended gaps in treatment

\begin{tabular}{|c|c|c|c|c|c|c|c|c|c|}
\hline Follow-up years & 1 & 2 & 3 & 4 & 5 & 6 & 7 & 8 & 9 \\
\hline$N^{\mathrm{d}}$ & 402,791 & 350,983 & 302,444 & 257,029 & 213,029 & 171,515 & 134,098 & 99,118 & 68,453 \\
\hline \multicolumn{10}{|l|}{ 60-day permissible gap } \\
\hline Persisted with therapy ${ }^{\mathrm{b}}$ & 63.1 & 46.4 & 36.8 & 30.1 & 25.0 & 20.9 & 17.6 & 14.8 & 12.2 \\
\hline Discontinued therapy ${ }^{\mathrm{c}}$ & 15.2 & 15.8 & 15.3 & 14.6 & 14.0 & 13.4 & 12.7 & 12.0 & 11.4 \\
\hline Reinitiated therapy & 21.7 & 37.8 & 47.9 & 55.3 & 61.0 & 65.7 & 69.7 & 73.2 & 76.4 \\
\hline One extended gap & 16.7 & 23.2 & 24.5 & 24.7 & 24.3 & 23.6 & 22.9 & 21.9 & 20.7 \\
\hline$\geq 2$ extended gaps & 5.0 & 14.6 & 23.4 & 30.6 & 36.7 & 42.1 & 46.8 & 51.3 & 55.7 \\
\hline \multicolumn{10}{|l|}{ 120-day permissible gap } \\
\hline Persisted with therapy & 76.7 & 63.5 & 54.8 & 48.1 & 42.7 & 38.0 & 34.4 & 30.8 & 27.4 \\
\hline Discontinued therapy ${ }^{\mathrm{c}}$ & 16.8 & 18.6 & 18.7 & 18.6 & 18.3 & 18.0 & 17.5 & 17.4 & 16.9 \\
\hline Reinitiated therapy & 6.5 & 17.9 & 26.5 & 33.3 & 39.0 & 44.0 & 48.1 & 51.8 & 55.7 \\
\hline One extended gap & 6.4 & 15.9 & 20.6 & 23.3 & 25.0 & 26.2 & 27.0 & 27.4 & 27.9 \\
\hline$\geq 2$ extended gaps & 0.1 & 2.0 & 5.9 & 10.0 & 14.0 & 17.8 & 21.1 & 24.4 & 27.8 \\
\hline
\end{tabular}

${ }^{\text {a }}$ Alendronate $(5,10$, and $70 \mathrm{mg}$ ), cyclical etidronate, risedronate (5 and $35 \mathrm{mg}$ ) identified from the Ontario Drug Benefit (ODB) program data, residents aged 66 or more years. First dispensing over entire period from April 1996 to March 2009 was considered the index date.

${ }^{\mathrm{b}}$ Persistence with therapy after index was defined as continuous treatment without a permissible gap.

${ }^{\mathrm{c}}$ Identified as the proportion of patients who did not persist with therapy, and did not reinitiate treatment in the respective follow-up period.

${ }^{d}$ Number of patients with complete follow-up data included and thus excludes those who died, moved out of the province, and if March 31,2009 occurred within the follow-up period. Proportions therefore cannot be compared directly over time. 


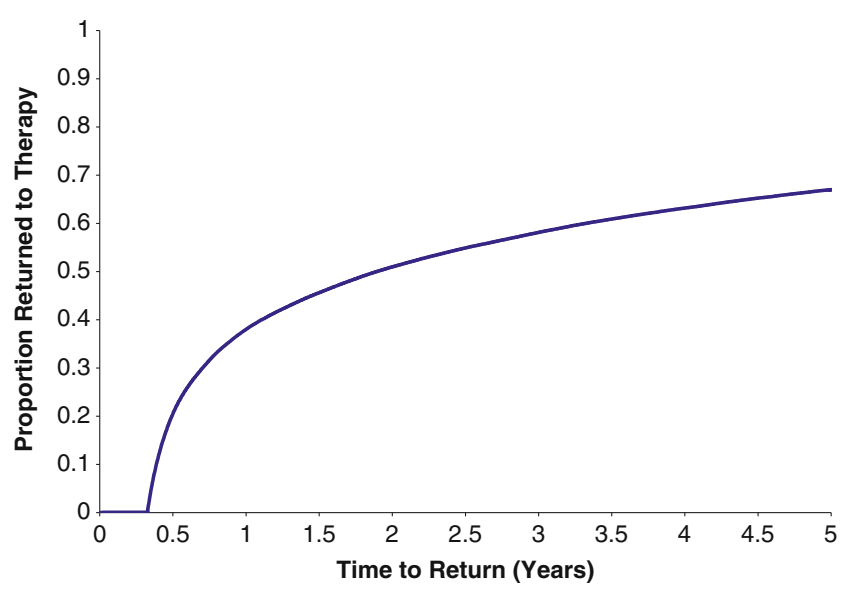

Fig. 2 Time until return to oral bisphosphonate therapy following a period of 120 days or longer without treatment among new users in Ontario aged 66 or more years, April 1996-March 2009

to 12.8 years. Among new users treated with alendronate or risedronate at the index date, only $5 \%$ switched therapy within one year and less than $10 \%$ switched over the length of follow-up.

\section{Discussion}

Our results are consistent with prior reports that indicate that persistence with bisphosphonate therapy is suboptimal [10-12]. Recent evidence suggests that uninterrupted bisphosphonate therapy for a minimum of 3-5 years is important to reduce fracture risk [24-27]. However, our results show that fewer than half of patients persist with therapy for 2 years, and only $25 \%$ persist with therapy for 5 years. Even when a more lenient permissible gap of 120 days was used to identify non-persistence, our findings identify that only $40 \%$ of patients persisted with therapy for 5 years. We also note that extending the permissible gap length from 60 to 120 days changed our estimates of persistence from $63 \%$ to $77 \%$ at 1 year, and from $25 \%$ to $43 \%$ at 5 years. These findings highlight the impact of length of follow-up and permissible gap on persistence measurement. Given the observed variation in persistence rates with different permissible gap lengths, we recommend that methodology be explicitly reported to facilitate study comparisons [13].

Regardless of the permissible gap length used to determine length of treatment persistence, our findings identify that extended gaps in oral bisphosphonate therapy are common, and the majority of patients experience more than one extended gap between bisphosphonate prescriptions. Although it is encouraging that many patients are returning to therapy, the clinical impact of the time off drug remains unknown, and requires further investigation. In fact, experiencing a fracture after stopping osteoporosis treatment has been found to be a significant predictor of reinitiating osteoporosis medication [20].

Our results also indicate that the longer the length of follow-up, the more likely it is that a patient will switch treatments. Over the entire study period of up to 12.8 years, $37 \%$ of all users $(51 \%$ of etidronate users) switched to a different oral bisphosphonate. In Ontario, etidronate has been available without restriction through the ODB program since 1996, thus permitting greater opportunity for patients to initiate etidronate and switch to another bisphosphonate over time. Although second generation bisphosphonates have been available since 1996 (daily alendronate), the initial listing status for both alendronate and risedronate required a trial of, or documented allergy to etidronate (2000-2003), or two of the following: (i) BMD T-score $\leq 3.0 \mathrm{SD}$, (ii) aged 75 or more years, (iii) prior osteoporosis-related fracture (2003-2007). Since 2007, all three agents have been covered without restrictions. Given that clinical trial data demonstrate reductions in non-vertebral fracture risk compared to placebo with use of alendronate and risedronate, but not etidronate [2, 28], it is not surprising that patients were observed to have switched from etidronate to alendronate or risedronate after treatment failure, or once access to these drugs through the ODB program became less restrictive. We identified that less than $10 \%$ of alendronate/risedronate users switched to a different bisphosphonate over follow-up, compared to $51 \%$ of etidronate users. Switching rates between bisphosphonates may be lower in regions such as the United States, where etidronate is not available.

Despite the decline in etidronate prescribing over time and the noted increase in the number of males being treated, we found little change over time in the percent of new users having had a BMD test or fracture. The slight increase in BMD testing seen between April 1996March 2000 and April 2000-March 2003 is likely attributable to the switch from DPA to DXA technology in 1998 and the increased number of DXA machines, from 95 in 1997 to 213 in 1998 [29]. Similarly, the slight increase in the proportion with hip, humerus or radius/ulna fracture within the year prior to index is likely related to the change in coding from ICD-9-CM to ICD-10-CA that occurred in 2002. While ICD-10-CA includes greater specification, previous studies have found sensitivity of $95 \%$ or higher for the identification of fractures using ICD-9-CM [30], and ICD-10-CA coding [17]. Our results therefore suggest little change in the importance of BMD testing or fracture history in guiding bisphosphonate therapy over our study period.

Three important study limitations are worth noting. First, we were unable to study patterns of bisphosphonate therapy among persons younger than 66 years. It is possible that prescribing patterns have changed over time in ways that 
we were unable to observed, such as prescribing pharmacotherapy at younger ages and prior to 66 years. It is also possible that some of the identified "new users" were prevalent users with private drug coverage that switched to coverage under the ODB program once these agents were covered by the public plan. However, recent data suggest good agreement between self-report and ODB pharmacy data for bisphosphonate use among older women (kappa statistic= $0.81,95 \% \mathrm{CI}=0.77-0.85$ [18]), and few seniors in Ontario do not access medications through the ODB program [14].

Second, we restricted our study to oral bisphosphonates, and thus it is possible that some users classified as nonpersistent with therapy may have switched to non-oral bisphosphonate therapy, such as calcitonin, raloxifene, teriparatide, or zoledronic acid. However, we expect this to have occurred in only a few patients, as calcitonin and teriparatide are not listed on the ODB formulary, and raloxifene and zoledronic acid are only available under restricted conditions. For example, zoledronic acid is only available among men and women unable to take oral medications. In addition, prior research has identified that those who return to osteoporosis therapy after an extended gap tend to return to the same drug class [20]. Thus, while we recognize that switching between osteoporosis therapies may be more common in regions with better access to non-bisphosphonate therapy, we expect this to be minimal in our sample. Further research using large claims databases in other regions will help clarify switching patterns.

Third, we recognize that some of our observed nonpersistence may have been physician directed due to the experience of, or concern for adverse drug events. Although oral bisphosphonates are generally well tolerated, upper gastrointestinal complaints are commonly reported in new users [31]. In addition, with recent concerns for possible increased risk for femoral shaft fractures after long-term bisphosphonate use [32], a physician directed drug holiday may be reasonable for those patients with more than 5 years of bisphosphonate use, and could account for some of the non-persistence seen beyond 5 years. While the median exposure was only 2.2 years, $25 \%$ of patients had 5 years of uninterrupted therapy, and $12 \%$ had 9 years of uninterrupted therapy.

Despite these limitations, our study has several strengths. We followed more than 450,000 new users of oral bisphosphonates for up to 12.8 years. This provided ample follow-up to characterize both drug switching and treatment reinitiation patterns. Our results indicate that most patients discontinue bisphosphonate therapy within 2 years and many experience more than one extended gap in bisphosphonate use. Although emerging evidence suggests that after 3-5 years of uninterrupted therapy a physician-directed drug holiday may be appropriate for many patients [24-26], further research is needed to clarify for which patients this may be suitable. In addition, we document that the majority of patients are not exposed to bisphosphonate therapy long enough to be considered for a physician-directed drug holiday, with a median length of exposure of only 2 years, and the majority experiencing one or more extended gaps in therapy.

Osteoporosis is a major public health concern that results in debilitating fractures. Oral bisphosphonates are first-line therapy for osteoporosis, and are effective in reducing fracture risk. Although other therapies are available, including nasal calcitonin, raloxifene, teriparatide, zoledronic acid, and most recently, denosumab; these agents are reserved as second or third line treatment options. Our results not only confirm findings from other countries by identifying sub-optimal rates of persistence with oral bisphosphonate, but our findings add to the literature by identifying the frequency of extended gaps and rate of return to therapy. We identify that many patients return to therapy following an extended gap; however, the clinical impact of this time away from therapy remains unknown. Further research is needed to identify predictors of non-persistence and to clarify when and among which patients a physician-directed drug holiday may be appropriate. Results may then be used to develop effective interventions that aim to improve the length of persistence and reduce the frequency of gaps in bisphosphonate therapy. It is through improved treatment rates among patients at high risk for fracture that we will we reduce the public impact of osteoporotic fractures.

Acknowledgements This research was supported by research grants from the Canadian Institutes of Health Research (CIHR) and the Ontario Ministry of Research Innovation (OMRI). Dr Cadarette holds a CIHR New Investigator Award in the Area of Aging and Osteoporosis and an OMRI Early Researcher Award. Andrea Burden holds the Graduate Department of Pharmaceutical Sciences 2010 Wyeth Pharmaceutical Fellowship in Health Outcomes Research and the 2010-2011 University of Toronto Bone and Mineral Group Scholarship (Clinical). Dr. Solomon receives salary support from Amgen for work on rheumatoid arthritis as well as support from the Arthritis Foundation, AHRQ, and the NIH (AR 055989, AR 047782) on osteoporosis and adherence. Dr. Mamdani has received honoraria for unrelated work from Pfizer, Eli Lilly, and Amgen within the past 3 years. Authors acknowledge Dr. M. Alan Brookhart for insightful discussions, Brogan Inc. for providing access to drug identification numbers used to identify eligible drugs, and Jin Luo at the Institute for Clinical Evaluative Sciences (ICES) for assistance with statistical analyses. ICES is a non-profit research corporation funded by the Ontario Ministry of Health and Long-Term Care. The opinions, results and conclusions are those of the authors and are independent from the funding sources. No endorsement by CIHR, ICES, OMRI or the Ontario Ministry of Health and Long-Term Care is intended or should be inferred.

\section{Conflicts of interest None.}

Open Access This article is distributed under the terms of the Creative Commons Attribution Noncommercial License which permits any noncommercial use, distribution, and reproduction in any medium, provided the original author(s) and source are credited. 


\section{Appendix}

Table 3 Medical claims used to identify covariates and exclusion criteria

\begin{tabular}{|c|c|}
\hline Variable & Coding definition \\
\hline BMD testing ${ }^{\mathrm{a}}$ & Any OHIP claim of: J654, J655, J656, J688, J854, J855, J856, J888, X145, X146, X149, X152, X153, X155 and X \\
\hline $\begin{array}{l}\text { Paget's disease } \\
\text { diagnosis }\end{array}$ & $\underline{\underline{\text { Any of ICD-9-CM }}}=731.0,731.1 ;$ or ICD-10-CA $=$ M88.x; or $\underline{\text { OHIP }}=731$ \\
\hline \multirow[t]{4}{*}{ Fracture history } & Thoracic vertebral fracture: \\
\hline & Any of ICD-9-CM $=805.2,805.3$ or ICD-10-CA $=$ S22.0x, S22.1x \\
\hline & Hip, humerus, radius or ulna: \\
\hline & $\begin{array}{l}\text { Any of ICD-9-CM }=733.11,733.12,733.14,812 . x, 813 . x, 820 . x ; \text { or ICD-10-CA } \\
\text { S72.0x, S72.1x, S72.2x; or OHIP }=812,813, \text { F027, F028, F030 }\end{array}$ \\
\hline
\end{tabular}

ICD-9-CM International Classification of Diseases, Ninth Revision, Clinical Modification; used prior to April 1, 2002; ICD-10-CA International Classification of Diseases, Tenth Revision, Canada; used since April 1, 2002; OHIP Ontario Health Insurance Plan claims database

${ }^{\text {a }}$ Sensitivity $=98 \%$, specificity $=93 \%[18]$

\section{References}

1. Burge R, Dawson-Hughes B, Solomon DH et al (2007) Incidence and economic burden of osteoporosis-related fractures in the United States, 2005-2025. J Bone Miner Res 22:465-475

2. MacLean C, Newberry S, Maglione M et al (2008) Systematic review: comparative effectiveness of treatments to prevent fractures in men and women with low bone density or osteoporosis. Ann Intern Med 148:197-213

3. Brown JP, Josse RG, Scientific Advisory Council of the Osteoporosis Society of Canada (2002) 2002 Clinical practice guidelines for the diagnosis and management of osteoporosis in Canada. Can Med Assoc J 167(10 Suppl):S1-S34

4. Jaglal SB, Weller I, Mamdani M et al (2005) Population trends in BMD testing, treatment, and hip and wrist fracture rates: are the hip fracture projections wrong? J Bone Miner Res 20:898-905

5. Imaz I, Zegarra P, Gonzalez-Enriquez J et al (2010) Poor bisphosphonate adherence for treatment of osteoporosis increases fracture risk: systematic review and meta-analysis. Osteoporos Int 21:1943-1951

6. Siris ES, Selby PL, Saag KG et al (2009) Impact of osteoporosis treatment adherence on fracture rates in North America and Europe. Am J Med 122:S3-S13

7. Wilkes MM, Navickis RJ, Chan WW, Lewiecki EM (2010) Bisphosphonates and osteoporotic fractures: a cross-design synthesis of results among compliant/persistent postmenopausal women in clinical practice versus randomized controlled trials. Osteoporos Int 21:1943-1951

8. Cadarette SM, Solomon DH, Katz JN, Patrick AR, Brookhart MA (2011) Adherence to osteoporosis drugs and fracture prevention: no evidence of healthy adherer bias in a frail cohort of seniors. Osteoporos Int 22:943-954

9. Papaioannou A, Kennedy CC, Dolovich L, Lau E, Adachi JD (2007) Patient adherence to osteoporosis medications: problems, consequences and management strategies. Drugs Aging 24:37-55

10. Kothawala P, Badamgarav E, Ryu S, Miller RM, Halbert RJ (2007) Systematic review and meta-analysis of real-world adherence to drug therapy for osteoporosis. Mayo Clin Proc 82:14931501
11. Melo M, Qiu F, Sykora K et al (2006) Persistence with bisphosphonate therapy in older people. J Am Geriatr Soc 54:1015-1016

12. Cramer JA, Gold DT, Silverman SL, Lewiecki EM (2007) A systematic review of persistence and compliance with bisphosphonates for osteoporosis. Osteoporos Int 18:1023-1031

13. Cadarette SM, Burden AM (2010) Measuring and improving adherence to osteoporosis pharmacotherapy. Curr Opin Rheumatol 22:397-403

14. Paterson JM, Suleiman A, Hux JE, Bell C (2008) How complete are drug history profiles that are based on public drug benefit claims? Can J Clin Pharmacol 15:e108-e116

15. Williams JI, Young W (1996) Appendix 1: A summary of studies on the quality of health care administrative databases in Canada. In: Goel V, Williams JI, Anderson GM, Blackstein-Hirsch P, Fooks C, Naylor CD (eds) Patterns of health care in Ontario, The ICES Practice Atlas. Canadian Medical Association, Ottawa

16. Richards J, Brown A, Homan C (2001) The data quality study of the Canadian Discharge Abstract Database. In Proceedings of Statistics Canada Symposium.

17. Juurlink D, Preyra C, Croxford R et al (2006) Canadian institute for health information discharge abstract database: a validation study. In ICES investigative report. Institute for Clinical Evaluative Sciences, Toronto

18. Cadarette SM, Jaglal SB, Raman-Wilms L, Beaton DE, Paterson JM (2011) Osteoporosis quality indicators using healthcare utilization data. Osteoporos Int 22:1335-1342

19. Ministry of Health and Long-Term Care (2005) Ontario Drug Benefit formulary/comparative drug index. In. Ministry of Health, Queen's Printer for Ontario

20. Brookhart MA, Avorn J, Katz JN et al (2007) Gaps in treatment among users of osteoporosis medications: the dynamics of noncompliance. Am J Med 120:251-256

21. Cramer JA, Amonkar MM, Hebborn A, Altman R (2005) Compliance and persistence with bisphosphonate dosing regimens among women with postmenopausal osteoporosis. Curr Med Res Opin 21:1453-1460

22. Lo JC, Pressman AR, Omar MA, Ettinger B (2006) Persistence with weekly alendronate therapy among postmenopausal women. Osteoporos Int 17:922-928 
23. Solomon DH, Avorn J, Katz JN et al (2005) Compliance with osteoporosis medications. Arch Intern Med 165:2414-2419

24. Geusens P (2009) Bisphosphonates for postmenopausal osteoporosis: determining duration of treatment. Curr Osteoporos Rep 7:12-17

25. Black DM, Schwartz AV, Ensrud KE et al (2006) Effects of continuing or stopping alendronate after 5 years of treatment. The Fracture Intervention Trial Long-Term Extension (FLEX): a randomized trial. JAMA 296:2927-2938

26. Watts NB, Chines A, Olszynski WP et al (2008) Fracture risk remains reduced one year after discontinuation of risedronate. Osteoporos Int 19:365-372

27. Curtis JR, Westfall AO, Cheng H, Delzell E, Saag KG (2008) Risk of hip fracture after bisphosphonate discontinuation: implications for a drug holiday. Osteoporos Int 19:1613-1620

28. Cranney A, Guyatt G, Griffith L et al (2002) IX: summary of meta-analyses of therapies for postmenopausal osteoporosis. Endocr Rev 23:570-578
29. Jaglal SB (2002) Bone mineral density testing. In: Stewart DE, Ferris L, Hyman I, Cohen M, Williams JI, Cheung A (eds) Ontario women's health status report. Institute for Clinical Evaluative Sciences, Toronto

30. Tamblyn R, Reid T, Mayo N, McLeod P, Churchill-Smith M (2000) Using medical services claims to assess injuries in the elderly: sensitivity of diagnostic and procedure codes for injury ascertainment. J Clin Epidemiol 53:183-194

31. Cryer B, Bauer DC (2002) Oral bisphosphonates and upper gastrointestinal tract problems: what is the evidence? Mayo Clin Proc 77:1031-1043

32. Shane E, Burr D, Ebeling PR et al (2010) Atypical subtrochanteric and diaphyseal femoral fractures: report of a task force of the American society for bone and mineral research. J Bone Miner Res 25:2267-2294

33. Cadarette SM, van Wijk BL, Patrick AR, Brookhart MA (2011) Adherence to pharmacotherapy for hypercholesterolemia, hypertension and osteoporosis: behavioral insights. Am J Pharm Ben, in press 